\title{
REDES SOCIAIS ONLINE E DEMOCRACIA MONITORADA: SOBRE COMENTÁRIOS MONITORES A INSTITUIÇÕES BRASILEIRAS NO FACEBOOK
}

\author{
Online social network and monitory democracy: about the monitories comments \\ to Brazilian institutions on Facebook
}

\section{Redes sociales en línea y democracia monitoreada: acerca de los comentarios monitores a instituciones brasileñas en el Facebook}

Fernanda Cavassana

Professora Colaboradora do Departamento de Jornalismo da UEPG

cavassanaf@gmail.com

Emerson Cervi

Professor Associado do Departamento de Ciência Política da UFPR

ecervi7@gmail.com

\section{Resumo}

O artigo discute formas contemporâneas de relacionamento de cidadãos com instituições democráticas dentro do contexto das redes sociais online. Para isso, são consideradas as publicações e as interações registradas em fanpages que alimentam o debate público no Facebook. Foram selecionadas doze instituições brasileiras, de diferentes dimensões de representação e níveis de institucionalização. Seus 37.807 posts e 12.995 .826 comentários formam o corpus, sendo o recorte temporal de sete meses, em 2017. A metodologia de análise é quantitativa e comparativa. Os resultados apontam uma tendência do comportamento monitor na fanpage ocorrer quanto maior for o nível de institucionalização da instituição. Também indicam, comparativamente, um nível fraco de engajamento do público com as fanpages dos partidos políticos.

Palavras-chave: Democracia monitorada. Redes sociais online. Instituições brasileiras.

\begin{abstract}
This paper discusses contemporary forms of relationship between citizens and their democratic representatives in the context of the online social networking. In this regard, it considered posts and its interactions on fanpages which foster the public debate on Facebook. Twelve Brazilians institutions from different representative scopes and levels of institutionalization were selected. Their 37.807 posts and 12.995.826 comments make up the corpus, with a temporal cut of seven months in 2017. The analysis methodology is comparative and quantitative. Overall, the results indicate that there is a tendency to happen monitory behavior in fanpages which greater level of institutionalization. Furthermore, comparatively, there is a low level of public engagement with political parties' fanpages.
\end{abstract}

Key words: Monitory democracy. Online social network. Brazilian institutions. 


\section{Resumen}

El artículo discute las formas contemporáneas de relación entre ciudadanos y las instituciones democráticas en el contexto de las redes sociales en línea. Se consideran las publicaciones y las interacciones registradas en las fanpages que hacen parte del debate en espacios semipúblicos como el del Facebook. Se seleccionaron doce instituciones brasileñas, de distintas dimensiones de representación y niveles de institucionalización. Sus 37.807 posts y 12.995.826 comentarios forman el corpus empírico, siendo el recorte temporal de siete meses de 2017. La metodología de análisis es cuantitativa y comparativa. Los resultados apuntan una tendencia del comportamiento monitor ocurrir cuanto más grande sea el nivel de institucionalización. También indican, comparativamente, un nivel débil de compromiso del público con las fanpages de los partidos políticos.

Palabras clave: Palabra clave. Palabra clave. Palabra clave.

\section{INTRODUÇÃO}

O artigo $^{1}$ discute manifestações e relações de cidadãos com instituições políticas e sociais dentro do contexto das redes sociais online, doravante RSO. Partimos da discussão sobre monitory democracy ${ }^{2}$ apresentada por John Keane $(2010 ; 2015 ; 2018)$. Esta perspectiva considera as relações contemporâneas entre representantes e representados dentro de uma conjuntura de excessos de produção, circulação e consumo de informações, além do aumento do monitoramento das instituições políticas por parte de atores, incluindo os cidadãos individuais, que atuam dentro e fora das delimitações do Estado. É compreensão de um novo estágio histórico das democracias que está relacionado diretamente à abundância comunicativa da Era Digital (KEANE, 2010; 2018).

Para tanto, analisam-se os comentários feitos às páginas oficiais de diferentes instituições representativas brasileiras no Facebook. São instituições que tradicionalmente atuam na mediação do debate público, produzindo e distribuindo conteúdos sobre temas políticos relevantes para a população. Assim, foram selecionadas 12 fanpages abarcando entidades da imprensa, partidos, movimentos sociais e perfis oficiais do Congresso Nacional e do Governo Federal do Brasil. Justifica-se a escolha do Facebook por ser um das RSO mais utilizada pelos brasileiros e pelas formas possíveis de interação que ela permite entre as pessoas e os perfis

\footnotetext{
${ }^{1}$ Versão preliminar deste foi apresentada no $56 .{ }^{\circ}$ Congresso ICA, em Salamanca em julho de 2018.

${ }^{2}$ Optamos por uma tradução livre de democracia monitorada.
} 
institucionais, como o ato de comentar - e monitorar - as publicações. Aqui, são considerados como monitores os comentários direcionados diretamente às instituições, independentemente dos temas sobre os quais elas postam para informar e alimentar o debate digital.

Tem-se como ponto de partida a seguinte questão: o nível de institucionalização dos representantes está relacionado ao volume de comentários-monitores? O objetivo é comparar a intensidade e a proporção dos comentários-monitores por nível de institucionalização e entre as fanpages. Assim, pretende-se verificar em que intensidade as instituições representativas brasileiras estão recebendo comentários-monitores em suas publicações nas RSO. Em sete meses, foram coletados quase 250 mil comentários monitores, feitos a quase 38 mil posts publicados pelas 12 fanpages consideradas aqui.

$\mathrm{O}$ artigo segue dividido em quatro partes. O primeiro tópico aborda o conceito de democracias monitoradas e a discussão sobre como as RSO intensificam as ações dos monitores democráticos individuais. O segundo trata do nosso objeto de estudo, discorrendo sobre as instituições brasileiras cujas fanpages foram analisadas e a relevância da atuação das mesmas em ambientes de debate digital como o Facebook. A terceira seção é destinada à análise empírica, que aborda de forma quantitativa e comparativa os dados. Por último, são feitas as considerações finais.

\section{MONITORAMENTO DEMOCRÁTICO EM RSO}

Para Keane (2010), as sociedades democráticas enfrentam uma nova fase que rompe fronteiras, funções e comportamentos consolidados ao longo do desenvolvimento e institucionalização da representação política. No atual estágio, elas são democracias monitoradas, cujas instituições representativas passam a ser acompanhadas e cobradas intensamente por diversos atores e organizações. De forma não institucionalizada, surgem monitores que passam a acompanhar os representantes e a discutir suas ações e decisões nos mais diversos ambientes e esferas. Esta prática é prevista por Schudson (1998) como possível exercício de cidadania mais participativa e já foi pesquisada empiricamente para o comportamento online (VAN DEN HOVEN, 2005). Contudo, Keane (2010) tende a alertar que seu excesso pode aumentar a desconfiança política e a crise de representatividade. A ação de monitorar não se restringe a acompanhar o funcionamento dos órgãos ou instituições monitorados, mas é caracterizada pela cobrança e pela crítica daquilo que se monitora (KEANE, 2010). Esse monitoramento é desorganizado, ocorrendo por meio de vários fluxos 
comunicativos nas dimensões da sociedade, fora do controle do Estado, como também ultrapassando os limites das nações.

Uma das causas desse comportamento é a abundância comunicativa (KEANE, 2015). As pessoas passaram a ter mais contato com muitas informações sobre a política e as instituições representativas, assim como descobriram e passaram a atuar em novos meios de comunicação, publicando e discutindo temas políticos. Esse cenário passa a se consolidar ao longo do século XX, com o desenvolvimento e maior consumo da comunicação midiática e eletrônica, como a televisiva, mas é com a Internet que se potencializa. Além disso, na perspectiva de Keane (2010), a falta de confiança nas instituições democráticas também é responsável pela expansão dos monitores, uma vez que sem confiar nos seus representantes, os órgãos e os monitores procuram realizar o escrutínio público entre si, fora das instâncias institucionais, de modo desorganizado, ou, não institucionalizado.

Nesse cenário contemporâneo de abundância comunicativa, as RSO foram percebidas como uma oportunidade de aproximação entre o cidadão e seus representantes (COLEMAN, 2005). Canais digitais com alto nível de interatividade poderiam permitir uma representação mais direta. Os cidadãos, por exemplo, estariam diante de novas oportunidades para serem ouvidos, além de acompanhar de perto a atuação daqueles que os representam, incluindo as instituições. Contudo, esses espaços também foram contaminados com fluxos informativos de outras naturezas e promovidos para outras finalidades. Além disso, é preciso que sejam consideradas as características próprias de ambientes online como as RSO enquanto espaço social, que se configuram de uma forma desorganizada e multifacetada (FEENSTRA, 2012; GROSSI, 2011; KEANE, 1995), distante do molde de uma única esfera pública, consolidada e organizada. Assim, com as RSO, evidencia-se o aumento da participação do tipo monitor individual, que não necessariamente contribui para o fortalecimento democrático.

Sobre as RSO como Facebook, destaca-se que não são um ambiente apropriado para deliberação via debate digital. Tampouco se constituíram, na prática, em um espaço para representação direta, como alguns autores mais otimistas previam, o que acarretaria grandes transformações da representação política na era digital (COLEMAN, 2005). Ao caracterizarem os ambientes digitais como as RSO para a prática da comunicação política, Blumer e Coleman $(2017$, p.4) afirmam que ele "é mais poroso, fragmentado e antitético à palavra final sobre qualquer assunto". Por outro lado, tais ambientes se tornaram propícios para a prática de monitoramento individual, como descrito por Keane (2010). Para o autor, a combinação do estágio de monitoramento das democracias com a abundância comunicativa 
cria fluxos permanentes e inquietantes de interações entre atores e instituições, que passam a interagir muitas vezes em oposição uns aos outros, afastando-se do alcance de consensos no debate digital, como também discorre Grossi (2011). Portanto, a grande interação não resulta, necessariamente, em participação, tampouco em comunicação eficaz. Muitas vezes, trata-se de ruídos.

É considerando esses pressupostos teóricos que o trabalho se voltará aos comentários monitores feitos a instituições brasileiras representativas em diferentes dimensões. Aqui, o monitor é o indivíduo que comenta nas páginas de instituições representativas da democracia brasileira, dirigindo-se a elas naquele espaço do comentário público. Independentemente da publicação e sua temática, o comentário faz referência ao responsável por ela, ao representante democrático. Antes da análise, a seção seguinte explica quais são essas dimensões e os representantes que tiveram suas fanpages analisadas.

\subsection{A presença das instituições representativas no Facebook}

As fanpages analisadas nesta pesquisa foram escolhidas considerando a caracterização do monitoramento como uma atividade que acompanha e questiona atores e instituições de diferentes esferas (KEANE, 2010) e a configuração do Facebook como um ambiente social que reúne diferentes instituições representativas e as aproximam de seus representados, dadas as potencialidades da comunicação online nas RSO (COLEMAN, 2005). Estão no Facebook os partidos políticos (SILVA, 2014; BRAGA ET AL., 2015), a imprensa tradicional (CERVI; MASSUCHIN; CARVALHO, 2016), como também as entidades estatais que representam o Governo Federal em seus diferentes poderes (LENHARD, 2016; DE PAULA ET AL., 2018). Entretanto, ao atuarem em RSO, compartilham o espaço com novas organizações e movimentos, nativos do ambiente online, que surgem, dento do cenário de abundância comunicativa na era digital (KEANE, 2015; FEENSTRA, 2012; SORJ, 2015). Produzindo conteúdos políticos nas redes online, todas atuam na mediação do debate digital e representam a sociedade brasileira em diferentes dimensões, dento do Estado e na própria esfera social.

A “institucionalização é o processo pelo qual organizações e procedimentos adquirem valor e estabilidade" (HUNGTINGTON, 1968, p. 12). Assim sendo, quanto maior o nível de institucionalização, maior estabilidade e conhecimento social compartilhado sobre ela a instituição possui. Se elevada for a institucionalização de determinada entidade, mais claras e estáveis as expectativas sociais em relação ao comportamento da mesma (MAINWARING; 
TORCAL, 2005). Aqui, o nível de institucionalização foi definido de modo comparativo, condicionado, portanto, pela escolha das demais instituições. Quanto mais tradicional e estatal for a entidade, mais estável e regrada será a representatividade que ela exerce. Com um nível muito alto de institucionalização, por exemplo, temos a dimensão estatal de representatividade, composta por fanpages oficiais dos poderes executivo e legislativo do Brasil. A página do Palácio do Planalto representa a atual gestão do Governo Federal, a Presidência da República, publicando conteúdos diretamente vinculados ao governo e a atuação do presidente. A dimensão também comporta as fanpages oficiais do Congresso Nacional: a do Senado Federal e a da Câmara dos Deputados. Nos dois casos, as publicações costumam divulgar as atividades e decisões do legislativo, bem como informar os cidadãos dos projetos de lei em tramitação no Congresso e em suas comissões. A fanpage do Senado, por exemplo, busca estimular o engajamento do público, principalmente via comentários para debater as propostas.

Já os partidos políticos são considerados como de dimensão estatal-social de representatividade, por atuarem na sociedade e no âmbito do Estado. Neste trabalho, selecionamos três dos mais importantes partidos brasileiros: Partido do Movimento Democrático Brasileiro (MDB), Partido da Social Democracia Brasileira (PSDB), e Partido dos Trabalhadores (PT). São os partidos que apresentam os maiores números de filiados e de senadores e deputados federais na atual legislatura. Apresentam, portanto, alto nível de institucionalização. No caso da dimensão social tradicional, são considerados aqui os veículos jornalísticos brasileiros, que convencionalmente atuam em outros ambientes, ainda que digitais, mas exploram o Facebook para difundir seus conteúdos. Optou-se pela seleção da Folha de S.Paulo (Folha) e de O Estado de S. Paulo (Estadão), por serem os dois jornais tradicionais de abrangência nacional de maior circulação no país e o G1 por ser a fanpage do portal do maior grupo de comunicação do país, o grupo Globo. Representam, portanto, a imprensa tradicional do país. Por ser essencialmente social e atuar de maneira independente da esfera estatal, seu nível de institucionalização diante dos demais grupos tende a ser baixo.

Por último, com o nível mais baixo de institucionalização, há as páginas do "novo social". As três instituições selecionadas representam segmentos distintos da sociedade brasileira, mas compartilham a característica de serem oriundas da era digital, atuarem na produção de conteúdo online, e explorarem o Facebook como canal de comunicação com seu público. Dentro da perspectiva de Keane (2010), são considerados monitores democráticos por também acompanharam e questionarem as demais instituições e esferas de poder. A 
primeira a compor o grupo é a Agência Pública, uma agência de jornalismo investigativo e independente. Difere-se da grande imprensa brasileira principalmente por não pertencer a nenhum grupo tradicional de comunicação e atuar de forma colaborativa, contando, inclusive, com financiamentos coletivos para sua atuação. Também atua na função de fact-checking por meio de iniciativas que verificam informações difundidas por atores e instituições em combate às fake news. A segunda é o Mídia Ninja, um grupo que se apresenta como uma 'rede de comunicação livre', pautada pela produção e distribuição coletivas de informação, especificamente, pela Internet. Ideologicamente de esquerda e com a bandeira da defesa pela democratização da comunicação, Mídia Ninja surgiu e se consolidou com as manifestações de rua em 2013 no Brasil, com a justificativa de fornecer uma cobertura das mobilizações alternativa à grande imprensa. Por fim, também compõe a dimensão "novo social", o Movimento Brasil Livre - MBL. O MBL é um movimento político de ideologia liberal que surgiu em 2014, como oposição ao governo da presidente Dilma Rousseff. Afirmam ser um movimento apartidário, contudo, muitos dos seus líderes já se filiaram a alguns partidos brasileiros para serem candidatos, alguns já eleitos nas últimas eleições. A sua página no Facebook possui muitos seguidores. Seus dados, assim como as informações das demais fanpages estão resumidos no próximo tópico, seção que descreve os procedimentos metodológicos a seguir.

\section{ANÁLISE EMPÍRICA}

Neste artigo, as técnicas de análise são predominantemente estatísticas e comparativas. Trata-se, portanto, de uma análise quantitativa a partir das métricas de interação fornecidas pela própria RSO. A pesquisa considerou sete meses de atividade, abrangendo os posts, os comentários e os dados de engajamento (tipos de interação) ocorridos de junho a dezembro de 2017 nas fanpages descritas na seção anterior, cujas informações estão resumidas no Quadro 1, a seguir.

\begin{tabular}{|c|c|l|}
\hline $\begin{array}{c}\text { Nível de } \\
\text { institucionalização }\end{array}$ & $\begin{array}{c}\text { Dimensão de } \\
\text { Representação }\end{array}$ & \multicolumn{1}{c|}{ Instituição Representativa (sigla) } \\
\hline \multirow{3}{*}{ Muito alto } & \multirow{3}{*}{ Estatal } & Palácio do Planalto (PLA) \\
\cline { 3 - 3 } & & Senado Federal (SENA) \\
\cline { 3 - 3 } & \multirow{3}{*}{ Alto } & Câmara dos Deputados (CAM) \\
\cline { 3 - 3 } & \multirow{2}{*}{ Estatal-social } & Partido do Movimento Democrático Brasileiro (MDB) \\
\cline { 3 - 4 } & & Partido dos Trabalhadores (PT) \\
\cline { 3 - 4 } & & Partido da Sócio-democracia Brasileira (PSDB) \\
\hline
\end{tabular}


PROGRAMA DE PÓS-GRADUAÇÃO EM COMUNICAÇÃO DA UNIVERSIDADE FEDERAL DE SANTA MARIA

\begin{tabular}{|c|c|c|}
\hline \multirow{3}{*}{ Baixo } & \multirow{3}{*}{$\begin{array}{c}\text { Social } \\
\text { tradicional }\end{array}$} & Jornal Folha de S.Paulo - Folha (FSP) \\
\hline & & Jornal O Estado de S. Paulo - Estadão (ESP) \\
\hline & & Portal de notícias G1 (G1) \\
\hline \multirow{3}{*}{ Muito baixo } & \multirow{3}{*}{ Novo social } & Movimento Brasil Livre (MBL) \\
\hline & & Mídia Ninja (NINJ) \\
\hline & & Agência Pública (AGE) \\
\hline
\end{tabular}

Quadro 1 - Sobre as instituições analisadas no Facebook

Fonte: os autores (2019).

A raspagem dos dados foi feita semanalmente nesse período temporal, por meio do aplicativo Netvizz, totalizando 37.807 posts e 12.995.826 comentários. Na dimensão do post, as interações consideradas são os compartilhamentos (shares), as curtidas (likes), reações bastante positivas (love), reações bastante negativas (angry) e os comentários. Na dimensão dos comentários, consideramos duas principais características neste trabalho. Primeiramente, para mensurar o comportamento monitor do público nesses posts, foi considerada a menção à página no comentário. Já para verificar a presença institucional no debate, classificam-se também os comentários feitos pelas próprias páginas (com_page) em seus respectivos posts, como forma de responder ao público ou acrescentar novo conteúdo.

Para comparar as fanpages, foram considerados os quatro grupos criados e mencionados na seção anterior, que classificam o nível de institucionalização. Descritos os procedimentos metodológicos, passamos à análise dos resultados no próximo tópico. Primeiramente, a análise quantitativa descreve os dados obtidos em todo o período e depois passa a realizar comparações entre as páginas e os níveis de institucionalização, evidenciando principalmente características pertinentes aos comentários monitores.

Considerando a nossa abrangência temporal de sete meses, testou-se, primeiramente, se havia diferenças estatisticamente significativas nos dados de cada fanpage, por mês analisado. Uma vez que os comportamentos - tanto das instituições quanto do público - não são controlados e não há um modelo ideal que seria esperado, foi importante verificar se houve mudanças significativas entre um mês e outro. Se não houver, poderemos comparar as atividades por fanpage em todo o período considerado a partir dos totais. O quadro 2 a seguir traz o resumo dos testes de variância de médias (ANOVA) aplicados aos grupos considerando a variável mês como fator determinante para as variáveis de interação.

O quadro indica que não houve diferenças significativas para o fator mês em nenhuma das variáveis consideradas, indicando independência temporal dos dados. Portanto, por mais que sejam bastante diferentes entre si, a administração das páginas e o público que interage com elas tendem a ter um comportamento constante no período considerado. Assim, 
a análise comparativa entre as fanpages e seus respectivos níveis de institucionalização se dará a partir dos totais obtidos ao longo dos sete meses.

\begin{tabular}{|l|c|c|}
\hline \multicolumn{1}{|c|}{ Variável } & F & p-value \\
\hline Posts & 1,665 & 0,141 \\
\hline Likes & 0,340 & 0,914 \\
\hline Shares & 0,372 & 0,895 \\
\hline Comments & 0,804 & 0,570 \\
\hline Monitores & 0,299 & 0,935 \\
\hline
\end{tabular}

Fonte: os autores (2019).

Já tabela 1, abaixo, traz as frequências descritivas das postagens, curtidas, compartilhamentos, comentários gerais e comentários monitores obtidas por fanpage e por mês. Elas estão expostas na tabela por nível de institucionalização, do mais alto ao mais baixo. A primeira informação a destacar é a grande variância entre as páginas. Tanto para a quantidade de posts no período, quanto para cada uma das variáveis de engajamento do público com a publicação, há uma atuação distinta entre as instituições na RSO, havendo aquelas que publicaram pouco, em uma média de 67,6 posts por mês, e aquelas que muito postaram, alcançando uma média de quase um mil posts por mês. Entre os engajamentos, há páginas que a média mensal ultrapassou os três milhões de compartilhamentos (G1), enquanto outra não alcançou a média de dois mil compartilhamentos (MDB). Ressalta-se também de início que a classificação por nível de institucionalização e dimensão de origem também não explica as diferenças entre as fanpages, havendo também elevada variância internamente nos grupos.

Observando, portanto, os totais, pode-se afirmar que o MBL, Estadão e a Mídia Ninja são, respectivamente, as páginas que mais publicaram no período, com mais de 6 mil posts cada. Também se destacam Portal G1 e Folha de S.Paulo, com mais de 5 mil posts cada, e o PT, com mais de 3 mil posts. Assim, o Partido dos Trabalhadores aproxima-se dos veículos jornalísticos tradicionais, dos produtores de conteúdo político digital Mídia Ninja e MBL. As demais fanpages não chegaram a um mil posts. Senado e PSDB totalizaram quase 900 publicações cada e com um total em torno de 500 posts, ficaram Planalto, Câmara e 
Agência Pública. Esta última distanciando-se tanto das demais páginas jornalísticas, quanto das demais instituições da dimensão "novo social".

Tabela 1 - Dados descritivos das fanpages por mês

\begin{tabular}{|c|c|c|c|c|c|c|c|c|c|}
\hline PG & Interação & Total & Média/mês & SD & PG & Interação & Total & Média/mês & SD \\
\hline \multirow{5}{*}{$\sum_{U}$} & Posts & 473 & 67,6 & 9,9 & \multirow{5}{*}{$\underline{\hat{\varepsilon}}$} & Posts & 565 & 80,7 & 3,3 \\
\hline & Likes & 124.623 & $17.803,3$ & $6.165,2$ & & Likes & 38.128 & $5.446,9$ & $2.925,1$ \\
\hline & Shares & 160.547 & $22.935,3$ & $24.647,9$ & & \begin{tabular}{|l|} 
Shares \\
\end{tabular} & 12.511 & $1.787,3$ & $1.600,2$ \\
\hline & Comments & 99.311 & $14.187,3$ & $12.757,0$ & & Comments & 18.654 & $2.664,9$ & $3.027,8$ \\
\hline & Monitores & 2.085 & 297,9 & 97,8 & & Monitores & 1.833 & 261,9 & 328,8 \\
\hline \multirow{5}{*}{$\underset{3}{\Xi}$} & Posts & 678 & 96,9 & 38,0 & \multirow{5}{*}{ 鸽 } & Posts & 892 & 127,4 & 22,0 \\
\hline & Likes & 285.708 & $40.815,4$ & $21.638,4$ & & \begin{tabular}{|l|} 
Likes \\
\end{tabular} & 321.674 & $45.953,4$ & $21.069,5$ \\
\hline & Shares & 85.326 & $12.189,4$ & $6.226,8$ & & Shares & 88.459 & $12.637,0$ & $6.878,8$ \\
\hline & Comments & 206.603 & $29.514,7$ & $10.978,8$ & & Comments & 69.955 & $9.993,6$ & $4.785,4$ \\
\hline & Monitores & 2.372 & 338,9 & 180,5 & & Monitores & 8.549 & $1.221,3$ & 701,5 \\
\hline \multirow{5}{*}{$\underset{\mathbf{r}}{\mathbb{s}}$} & Posts & 894 & 127,7 & 8,5 & \multirow{5}{*}{$E$} & Posts & 3.133 & 447,6 & 124,2 \\
\hline & Likes & 4.386 .377 & $626.625,3$ & $177.681,3$ & & Likes & 2.809 .344 & $401.334,9$ & $161.308,8$ \\
\hline & Shares & 2.822 .998 & $403.285,4$ & $95.833,8$ & & \begin{tabular}{|l} 
Shares \\
\end{tabular} & 797.034 & $113.862,0$ & $44.818,5$ \\
\hline & Comments & 1.023 .559 & $146.222,7$ & $31.314,1$ & & Comments & 384.246 & $54.892,3$ & $17.481,4$ \\
\hline & Monitores & 38.356 & $5.479,4$ & $1.620,1$ & & Monitores & 34.817 & $4.973,9$ & $1.200,2$ \\
\hline \multirow{5}{*}{$\hat{\mathscr{\vartheta}}$} & Posts & 6.538 & 934,0 & 632,6 & \multirow{5}{*}{$\frac{1}{4}$} & Posts & 536 & 76,6 & 13,3 \\
\hline & Likes & 5.199 .817 & $742.831,0$ & $493.739,2$ & & Likes & 97.188 & $13.884,0$ & $2.542,3$ \\
\hline & Shares & 1.209 .781 & $172.825,9$ & $137.533,9$ & & Shares & 52.430 & $7.490,0$ & $2.195,4$ \\
\hline & Comments & 1.691 .443 & $241.634,7$ & $144.839,2$ & & Comments & 8.598 & $1.228,3$ & 206,9 \\
\hline & Monitores & 13.020 & $1.860,0$ & 798,3 & & Monitores & 273 & 39,0 & 8,5 \\
\hline \multirow{5}{*}{$\overrightarrow{\widehat{D}}$} & Posts & 5.365 & 766,4 & 721,8 & \multirow{5}{*}{$\bar{\varepsilon}$} & Posts & 6.915 & 987,9 & 267,8 \\
\hline & Likes & 3.542 .236 & $506.033,7$ & $530.905,6$ & & Likes & 24.111 .098 & $3.444 .442,6$ & $499.798,2$ \\
\hline & Shares & 1.023 .575 & $146.225,0$ & $127.915,9$ & & Shares & 12.122 .939 & $1.731 .848,4$ & $311.251,0$ \\
\hline & Comments & 1.222 .793 & $174.684,7$ & $147.392,3$ & & Comments & 2.909 .199 & $415.599,9$ & $56.251,5$ \\
\hline & Monitores & 22.351 & $3.193,0$ & $2.839,0$ & & Monitores & 96.519 & $13.788,4$ & $2.344,9$ \\
\hline \multirow{5}{*}{5} & Posts & 5.460 & 780,0 & 270,2 & \multirow{5}{*}{$\overrightarrow{\mathbf{Z}}$} & Posts & 6.479 & 925,6 & 461,2 \\
\hline & Likes & 24.726 .364 & \begin{tabular}{|l|}
$3.532 .337,7$ \\
\end{tabular} & $1.375 .467,6$ & & Likes & 4.512 .195 & $644.599,3$ & $303.701,4$ \\
\hline & Shares & 3.525 .586 & $503.655,1$ & $277.089,3$ & & Shares & 2.756 .670 & $393.810,0$ & $222.788,9$ \\
\hline & Comments & 4.353 .882 & $621.983,1$ & $258.934,3$ & & Comments & 1.007 .583 & $143.940,4$ & $69.436,9$ \\
\hline & Monitores & 18.603 & $2.657,6$ & $1.423,7$ & & Monitores & 10.402 & $1.486,0$ & 613,4 \\
\hline
\end{tabular}

Fonte: os autores (2019).

Já em relação à participação do público, nota-se que curtir o post é a ação mais realizada pelo público, seguido do compartilhamento em todas as páginas, com exceção do Portal G1, em que há ainda maior participação do público via comentários. O G1 totalizou quase 25 milhões de curtidas, mais de 4 milhões de comentários e de 3 milhões de compartilhamentos de suas publicações no Facebook durante os sete meses considerados. $\mathrm{O}$ MBL também se destaca, com mais de 24 milhões de curtidas, 12 milhões de compartilhamentos e quase 3 milhões de compartilhamentos de seus posts no período.

Entre as instituições da dimensão estatal, o Senado Federal se destaca com mais de 4 milhões de curtidas, quase 3 milhões de compartilhamentos e um milhão de comentários. Já 
entre os partidos políticos, o PT é aquele que registrou maior participação do público, dez vezes mais que os demais, com quase 3 milhões de curtidas em seus posts, quase 800 mil compartilhamentos e 400 mil comentários. Entre os veículos tradicionais de imprensa, Estadão e Folha apresentam números próximos, cerca de um milhão de compartilhamentos e comentários, ainda que o Estadão tenha totalizado mais curtidas, 5,2 milhões, que os 3,5 milhões da Folha. Na última dimensão, Mídia Ninja também alcançou milhões de engajamento, contudo seis vezes menos curtidas e compartilhamentos em seus posts que o MBL, já destacado. Assim, diante das demais páginas, a Câmara dos Deputados, o Palácio do Planalto, os partidos MDB e PSDB e a Agência Pública apresentaram pouca frequência de engajamento do público com suas publicações. Especificamente sobre a menção às instituições nos comentários, classificados como monitores nesta pesquisa, o MBL foi a página que se destacou, com quase 100 mil, quase 10 vezes menos que o Mídia Ninja. Os veículos jornalísticos também totalizaram dezenas de milhares de comentários desse tipo, assim como a página do Senado Federal, com quase 40 mil, e do PT, com 34 mil comentários monitores. A Agência Pública foi aquela que também apresentou menor monitoramento do público via comentários, considerando aqueles que a mencionavam textualmente.

Considerando que a participação do público nas fanpages pode ser incentivada ou condicionada pela participação da própria instituição - na forma de posts - comparamos também o nível de engajamento do público por post em cada fanpage, como a Tabela 2 aponta a seguir. Aqui, os totais obtidos para curtidas, compartilhamentos e comentários nas publicações foram divididos pelo total de posts, gerando uma média das atividades para cada fanpage. Conforme a tabela, a página do Senado é aquela em que há maior participação do público por post, tendo em média quase 5 mil curtidas, 3 mil compartilhamentos e um mil comentários, deles 42,9 comentários monitores em média. Assim, é a instituição com maior média de engajamento e monitoramento entre as analisadas.

Tabela 2 - Médias dos tipos de interação nas fanpages por post

\begin{tabular}{lrrrrr}
\hline Fanpage & Likes & Shares & Comments & Monitores & \%Monitores \\
\hline CAM & 263,47 & 339,42 & 209,96 & 4,41 & 0,48 \\
PLA & 421,40 & 125,85 & 304,72 & 3,50 & 0,87 \\
SENA & $4.906,46$ & $3.157,72$ & $1.144,92$ & 42,90 & 0,27 \\
\hline MDB & 67,48 & 22,14 & 33,02 & 3,24 & 0,10 \\
PSDB & 360,62 & 99,17 & 78,42 & 9,58 & 0,08 \\
PT & 896,69 & 254,40 & 122,64 & 11,11 & 0,11 \\
\hline ESP & 795,32 & 185,04 & 258,71 & 1,99 & 1,30 \\
FSP & 660,25 & 190,79 & 227,92 & 4,17 & 0,55 \\
G1 & $4.528,64$ & 645,71 & 797,41 & 3,41 & 2,34 \\
\hline AGE & 181,32 & 97,82 & 16,04 & 0,51 & 0,31
\end{tabular}




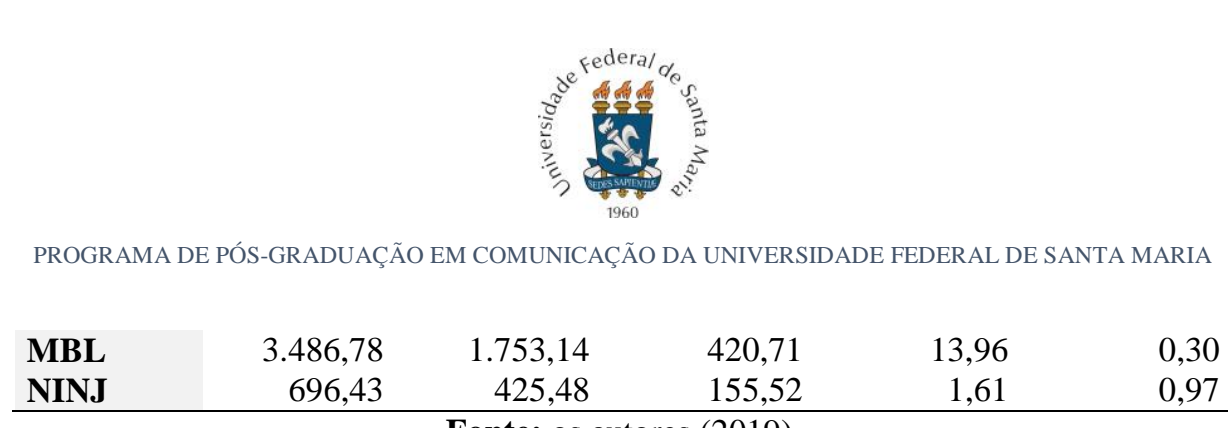

Fonte: os autores (2019).

Em seguida, destacam-se os posts do Portal G1, com 4,5 mil curtidas, 645 compartilhamentos, 797 comentários e ao menos três comentários monitores em média. A terceira fanpage cujos posts apresentam médias elevadas de engajamento é o MBL com quase 3,5 mil curtidas, 1,8 mil compartilhamentos e 420 comentários, quase 14 monitores. A Tabela 2 também destaca a fanpage do PT, a quarta com maiores médias de engajamento e a terceira no que diz respeito ao monitoramento, evidenciando assim uma menção textual ao partido a cada 10 comentários feitos aos seus posts. Em relação à análise anterior, da Tabela 1, nota-se como principal diferença a diminuição da importância das páginas da imprensa tradicional, com exceção do Portal G1, que ainda se destaca quando se consideram as médias por post. Isso se deve ao elevado número de posts que essas páginas jornalísticas publicam constantemente.

A coluna da direita da Tabela 2 mostra o percentual da média de comentários monitores em relação à média de comentários por post e página. Entre as páginas do primeiro grupo, as instituições estatais, a média de monitores é de $0,54 \%$ de comentários. Já entre os partidos políticos a média cai para 0,10 , com pouca variação entre eles. As maiores médias são para os jornais tradicionais, com 1,4\% de comentários monitores. Em seguida, as novas instituições apresentam média de 0,53\% de comentários monitores. Ou seja, menos de um monitor em média para cada 100 comentários.

Feitas as análises entre as páginas até aqui, a comparação passa a se dar por nível de institucionalização, agrupando os dados. Portanto, as particularidades de cada fanpage, identificadas na fase descritiva anterior não são consideradas. A hipótese a ser testada é de que quanto maior o nível de institucionalização da página, maior será a participação do tipo monitor. A partir daqui, outros dados também são considerados, como os engajamentos do tipo reações "love" e "angry" e a participação institucional da página também na seção de comentários, uma vez que foi possível mensurar a quantidade de vezes em que a administração da fanpage respondeu a comentários do público em seus próprios posts (com_page). Tais variáveis serão exploradas na análise na tentativa de explicar a maior ou menor presença de comentários monitores por nível de institucionalização.

A Tabela 3 sumariza os dados para os grupos a partir do nível de institucionalização. A primeira informação a se destacar é a grande diferença no total de posts, sendo que o nível 
"muito baixo" publicou sete vezes mais que o nível "muito alto". Também se nota que há diversas diferenças entre os grupos e que elas não são padronizadas, variando os grupos de institucionalização que se destacam na totalização de um ou outro tipo de interação. Enquanto o "muito baixo" destaca-se em compartilhamentos, o "baixo" totaliza o maior número de comentários e de reação de irritação. Para todas as variáveis, os partidos, que representam o nível alto de institucionalização, são os que possuem menores quantidades de publicações e dos tipos de interações do público, com a exceção do monitoramento, cuja média por post só é inferior à média da categoria muito alto.

Tabela 3 - Totais e médias por post para cada nível de institucionalização

\begin{tabular}{l|l|rrrrrrr}
\hline \multicolumn{2}{l}{ Institucionalização } & \multicolumn{1}{c}{ Shares } & \multicolumn{1}{c}{ Likes } & \multicolumn{1}{c}{ Love } & Angry & Comments & Com_page & Monitores \\
\hline Muito & Total & 14.932 .039 & 28.720 .481 & 1.385 .566 & 2.630 .361 & 3.925 .380 & 1.756 & 107.194 \\
baixa & Média/post & $1.071,9$ & $2.061,8$ & 99,5 & 188,8 & 281,8 & 0,13 & 7,70 \\
\hline Baixa & Total & 5.758 .942 & 33.468 .417 & 2.829 .270 & 3.557 .714 & 7.268 .118 & 781 & 53.974 \\
& Média/post & 331,7 & $1.927,6$ & 162,9 & 204,9 & 418,6 & 0,04 & 3,11 \\
\hline Alta & Total & 898.004 & 3.169 .146 & 209.885 & 85.751 & 472.855 & 916 & 45.199 \\
& Média/post & 195,6 & 690,4 & 45,7 & 18,7 & 103,0 & 0,20 & 9,85 \\
\hline Muito & Total & 3.057 .594 & 4.796 .708 & 558.501 & 878.378 & 1.329 .473 & 1.949 & 42.813 \\
alta & Média/post & $1.589,2$ & $2.493,1$ & 290,3 & 456,5 & 691,0 & 1,01 & 22,25 \\
\hline
\end{tabular}

Fonte: os autores (2019).

Em relação aos monitores, quanto menor a institucionalização da instituição que a fanpage representa, maior a quantidade totalizada de comentários monitores. Contudo, essa percepção se altera completamente quando se pondera o monitoramento pela quantidade de posts, pois as páginas mais institucionalizadas são aquelas que menos publicam. Assim, notase que quanto maior o nível de institucionalização, maior tende a ser a média de monitores por post. Apenas o grupo dos veículos jornalísticos, de baixa institucionalização, foge à tendência, apresentando menor média. O gráfico abaixo ilustra a comparação entre os grupos. Visualmente, ressalta-se o pouco destaque do grupo dos partidos, de alto nível de institucionalização; a baixa participação das próprias fanpages na seção de comentários de seus respectivos posts, muito próximo a zero em todos os grupos; e a tendência de crescimento dos comentários monitores para os maiores nível de institucionalização das páginas. Observa-se que, nas médias por post, o grupo de maior institucionalização é aquele que mais se destaca, em todos os tipos de interação. 


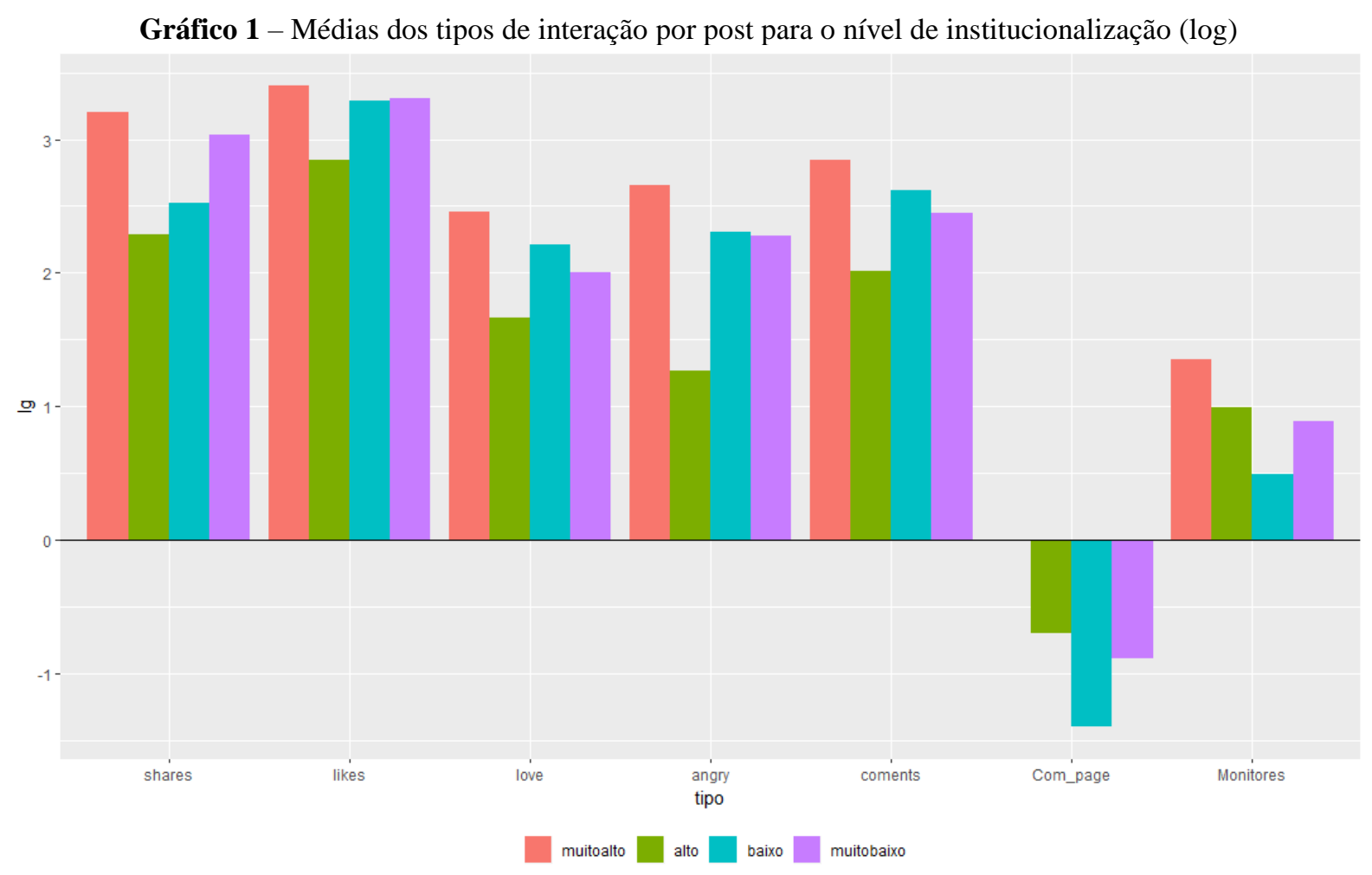

Fonte: os autores (2019).

Tendo realizadas as comparações por fanpage e por nível de institucionalização, nossa análise empírica passa a comparar a ocorrência dos tipos de interação com o monitoramento via comentários. Para isso, a tabela 4, abaixo, sumariza os dados dos testes de correlação. A partir dela, afirma-se que a ocorrência de comentários monitores é comum em posts em que há os demais tipos de interação do público, mas não possui uma correlação significativa com a média de comentários feitos pela própria fanpage nos posts. A principal correlação da média de comentários monitores se dá com a média de compartilhamentos por post nessas fanpages, o que representa a maior circulação do post pelo ambiente do Facebook.

Tabela 4 - Matriz de correlação entre as médias por post dos tipos de interação

\begin{tabular}{lccccccc}
\hline & Monitores & Com_page & Comments & Likes & Angry & Love & Shares \\
\hline Monitores & - & $-0,130$ & 0,741 & 0,667 & 0,703 & 0,800 & 0,914 \\
Com_page & $-0,130$ & - & $-0,082$ & $-0,308$ & 0,113 & $-0,260$ & $-0,212$ \\
Comments & $\mathbf{0 , 7 4 1}$ & $-0,082$ & - & 0,916 & 0,955 & 0,969 & 0,830 \\
Likes & $\mathbf{0 , 6 6 7}$ & $-0,308$ & 0,916 & - & 0,848 & 0,907 & 0,828 \\
Angry & $\mathbf{0 , 7 0 3}$ & 0,113 & 0,955 & 0,848 & - & 0,880 & 0,797 \\
Love & $\mathbf{0 , 8 0 0}$ & $-0,260$ & 0,969 & 0,907 & 0,880 & - & 0,858 \\
Shares & $\mathbf{0 , 9 1 4}$ & $-0,212$ & 0,830 & 0,828 & 0,797 & 0,858 & - \\
\hline
\end{tabular}

Fonte: os autores (2019). 
Já o tipo de comentário feito pela própria página, geralmente em resposta aos comentários do público, assim como apresentou com os comentários monitores, possui correlações negativas com os demais tipos de interação, com exceção da reação "angry”, que indica a irritação do usuário com o post. Ainda que baixa $(0,113)$, é positiva. Ou seja, os administradores das páginas não tendem a comentar em suas próprias publicações, participando do debate e respondendo os comentadores quando há tendência de comentários que mencionam a instituição. Contudo, tende-se a ter maior atuação institucional no debate nas fanpages em que se registram maiores médias de reação negativa ao post, em forma de emoji.

\section{CONSIDERAÇÕES}

Somando-se aos trabalhos que analisam quantitativamente as participações nas relações democráticas via redes sociais online (RSO), a contribuição aqui se dá principalmente pela delimitação do nosso objeto empírico - que perpassa e compara partidos, poderes executivo e legislativo, imprensa tradicional e alternativa, e novos movimentos sociais - e a abordagem teórica de Keane $(2010 ; 2015 ; 2018)$, sobre o atual estágio de monitoramento das democracias diante dos abundantes fluxos comunicativos. Consideramos um período de sete meses que totaliza mais de 200 dias de atividades nessas 12 fanpages de instituições democráticas, que são representantes da sociedade brasileira, especialmente no que se diz respeito à mediação do debate público. Atuando no Facebook, tais entidades produzem e distribuem conteúdos políticos para circulação nos debates e conversações digitais em RSO. Também se aproximam de suas audiências que interagem com as publicações, inclusive com monitoramento dos representantes via comentários.

Nosso primeiro resultado mostrou que as atividades nas fanpages mantêm-se constante, independente de mudanças temporais fora de período eleitoral. Isso ocorre tanto com aquelas promovidas pela instituição, quanto as resultantes da interação do público. Até a quantidade de comentários do público que mencionam as instituições, classificados aqui como monitores, segue padronizada por fanpage, sem significativas distinções temporais. Isso indica a estabilidade de produção de conteúdo e de participação, ainda que seja menor ou maior na comparação com as demais. Algumas fanpages se destacaram na publicação de posts 
como as dos veículos tradicionais de comunicação e os novos movimentos que nasceram utilizando os meios digitais para sua própria produção de conteúdo, como o MBL e Mídia Ninja. Entre os partidos, o PT é aquele que apresenta maiores números, de posts e interações, incluindo os comentários monitores. Já o Senado, que integra o grupo do mais elevado nível de institucionalização, é a página que apresenta as maiores médias de interação do público por post, incluindo a maior concentração de comentários monitores.

Quando consideramos os níveis de institucionalização nos quais agregamos as páginas, diminuem-se as diferenças entre elas. Isso porque há casos de fanpages mais e menos ativas em todos os grupos. Contudo, duas características passam a ser claramente evidenciadas. Primeiramente, observa-se que os partidos políticos, classificados como de alto nível de institucionalização, por serem tradicionais na política brasileira e atuarem nas dimensões social e estatal, são aqueles que apresentam médias menores de participação do público com os posts. Ressalta-se, porém, a exceção para o comentário do tipo monitor, em que a média do grupo dos partidos é a menor apenas que a média das páginas estatais, de muito alto nível de institucionalização. Isso se relaciona à segunda característica evidenciada na comparação dos grupos que é a tendência de haver mais comentários monitores conforme aumenta o nível de institucionalização, como ficou ilustrado no Gráfico 1. A exceção aqui se dá com o nível baixo, dos veículos tradicionais, que apresentaram a menor média de comentário monitor entre os demais. Portanto, nossa hipótese é parcialmente confirmada.

Os demais resultados estatísticos indicaram que os comentários monitores tendem a ocorrer de forma conjunta com outros tipos de interação do público com o post, especialmente o compartilhamento. Contudo, não há correlação com a participação da própria página na seção dos comentários (com_page), como também poderia se supor. Como os monitores aqui são considerados os comentários que mencionam a instituição, uma das estratégias para manter a participação do público naquele espaço poderia ser a maior presença de comentários respostas da própria página. Não é o que ocorre, não havendo correlação entre esses dois tipos de comentários. Os comentários institucionais são mais presentes nas páginas estatais, como o Gráfico 1 apontou, e tendem a ocorrer em post que também apresentam maiores médias de reações negativas (angry) ao conteúdo do post.

Os comentários monitores podem ainda serem analisados de outras formas, considerando ou não os níveis de institucionalização e as dimensões de origem das páginas. Outros trabalhos futuros podem, por exemplo, explorar técnicas de análise de conteúdo automatizada para classificar sentimentos expressos pelos monitores, ou realizar a 
classificação dos conteúdos das publicações procurando identificar se há determinados temas que ou formatos de posts que tendem a levar a maiores ou menores níveis de interações, incluindo as do tipo comentário monitor.

\section{REFERÊNCIAS}

Blumer, Jay \& Coleman, Stephen (2017). Democracy and the Media - Revisited. Journal of the European Institute for Communication and Culture, 22(2), pp. 111-128.

Braga, Sérgio, Rocha, Leonardo \& Carlomagno, Marcio (2015). A Internet e os partidos políticos brasileiros. Cadernos Adenauer, 16(3), pp. 47-74.

Cervi, Emerson, Massuchin, Michele \& Cavassana de Carvalho, Fernanda (2016). Internet $e$ eleições no Brasil. Curitiba: CPOP.

Coleman, Stephen (2005). New mediation and direct representation: reconceptualizing representation in the digital age. New Media \& Society, 7(2), pp. 177-198.

DePaula, Nic, Dincelli, Ersin \& Harrison, Teresa (2018). Toward a typology of government social media communication. Government Information Quarterly, 35, pp. 98-108.

Feenstra, Ramón (2012). Democracy in the age of new media galaxy. Veritas, 57 (1), pp. 112127.

Grossi, Giorgio (2011). "Sfera pubblica e flussi di comunicazione nell'epoca della rete". In: Mosca, Lorenzo \& Vaccari, Cristian (eds.). Nuovi media, nuova politica? Partecipazione e mobilitazione online. Milano: Franco Angeli.

Hungtington, Samuel (1968). Political order in changing societies. New Haven: University Press.

Keane, John (1995). Structural transformations of the public sphere. In: Communication Review (The), 1(1), pp. 1-22.

Keane, John (2010). Vida e Morte da Democracia. São Paulo: Edições 70.

Keane, John (2015). Democracy and media decadence. Cambridge: Cambridge University Press.

Keane, John (2018). Power and humility: the future of monitory democracy. Cambridge: Cambridge University Press.

Lenhard, Pedro Henrique (2016). Redes sociais e governo eletrônico: o papel do Facebook na promoção do e-legislativo no Brasil. Dissertação (Mestrado Profissional em Administração Pública). Rio de Janeiro: FGV. 
Mainwaring, Scott \& Torcal, Mariano (2005). Teoria e institucionalização dos sistemas partidários após a terceira onda de democratização. Opinião Pública, 11(2), pp. 249-286.

Rieder, Bernhard (2013). "Studying Facebook via data extraction: the Netvizz application". In: Proceedings of the 5th annual ACM web science conference. ACM, 2013. pp. 346-355.

Schudson, Michael (1998). The good citizen: A history of American civic life. New York: The Free Press.

Silva, Roberto (2014). "Mídias sociais e política: os partidos no Facebook”. Alceu, 14(28), pp. 202-223.

Sorj, Bernardo (2015). "On-line/off-line: a nova onda da sociedade civil e a transformação da esfera pública". In: Sorj, Bernardo \& Fausto, Sérgio (eds.). Internet e mobilizações sociais. São Paulo: Edições Plataforma Democrática.

Van Den Hoven, Jeoren (2005). E-democracy, E-Contestation and the Monitorial Citizen. Ethics and Information Technology, 7(2), pp. 51-59.

Original recebido em: 24 de fevereiro de 2019

Aceito para publicação em: 13 de maio de 2019

\section{Fernanda Cavassana de Carvalho}

Professora Colaboradora do Departamento de Jornalismo da Universidade Estadual de Ponta Grossa. Doutoranda em Ciência Política e mestra em Comunicação pela Universidade Federal do Paraná.

Especialista em Administração de Marketing e Propaganda pela Universidade Estadual de Londrina e graduada em Comunicação Social - Jornalismo pela mesma instituição. Pesquisadora do grupo de pesquisa em Comunicação Política e Opinião Pública (CPOP). Atua em pesquisas sobre internet e política; redes sociais online; mídia e eleições; campanhas eleitorais; jornalismo político.

Emerson Urizzi Cervi

Professor associado do Departamento de Ciência Política, do Programa de Pós-graduação em Ciência Política e do Programa de Pós-graduação em Comunicação da Universidade Federal do Paraná. Doutor em Ciência Política pelo Instituto Universitário de Pesquisas do Rio de Janeiro. Possui estágio pós-doutoral em partidos e eleições na Faculdade Latinoamericana de Ciências Sociais- Espanha

(Flacso-es)/Universidad Salamanca com financiamento Capes na modalidade de bolsa de estudos para estágio sênior no exterior (2015-2016). Coordena o grupo de pesquisa em Comunicação Política e

Opinião Pública (CPOP), com pesquisas e publicações nas áreas de debate e opinião pública, eleições, partidos, comunicação eleitoral, financiamento de campanhas e metodologia de pesquisa.

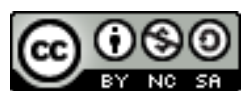

Esta obra está licenciado com uma Licença Creative Commons Atribuição-NãoComercial-CompartilhaIgual 4.0 Internacional 